\title{
The effects of sildenafil and acetazolamide on breathing efficiency and ventilatory control during hypoxic exercise
}

\author{
Sophie Lalande, \\ Division of Cardiovascular Diseases, Mayo Clinic, College of Medicine, Rochester, MN 55905, USA \\ Human Integrative and Environmental Physiology Laboratory, Division of Cardiovascular Diseases, \\ Mayo Clinic, Joseph 4-221, 200 First Street SW, Rochester, MN 55905, USA e-mail: \\ lalande.sophie@mayo.edu
}

Eric M. Snyder,

Department of Pharmacy Practice and Science, University of Arizona, Tucson, AZ 85721, USA

Thomas P. Olson,

Division of Cardiovascular Diseases, Mayo Clinic, College of Medicine, Rochester, MN 55905, USA

Minelle L. Hulsebus,

Division of Cardiovascular Diseases, Mayo Clinic, College of Medicine, Rochester, MN 55905, USA

Marek Orban,

Division of Cardiovascular Diseases, Mayo Clinic, College of Medicine, Rochester, MN 55905, USA

Virend K. Somers,

Division of Cardiovascular Diseases, Mayo Clinic, College of Medicine, Rochester, MN 55905, USA

Bruce D. Johnson, and

Division of Cardiovascular Diseases, Mayo Clinic, College of Medicine, Rochester, MN 55905, USA

Robert P. Frantz

Division of Cardiovascular Diseases, Mayo Clinic, College of Medicine, Rochester, MN 55905, USA

\begin{abstract}
The reduced arterial oxygen tension at high altitude impairs the ability to work. Acetazolamide improves arterial oxygen saturation $\left(\mathrm{SaO}_{2}\right)$ by increasing ventilation but is associated with an increased work and cost of breathing. Depending on the settings, sildenafil can also increases $\mathrm{SaO}_{2}$ possibly through a reduction in pulmonary hypertension and interstitial edema, which could improve ventilation-perfusion matching. The objective of this study is to determine the effects of acetazolamide and sildenafil on ventilatory control and breathing efficiency $\left(V_{\mathrm{E}} / V \mathrm{CO}_{2}\right)$ during submaximal steady-state hypoxic exercise in healthy individuals. Following $18 \mathrm{~h}$ of hypoxic exposure in an altitude tent at an oxygen concentration of $12.5 \%$ (simulated altitude of $4,300 \mathrm{~m}$ ), 15 participants performed $10 \mathrm{~min}$ of hypoxic exercise on a stationary bicycle at $40 \%$ of their sea level peak oxygen uptake $\left(V \mathrm{O}_{2}\right)$ while randomly receiving sildenafil $40 \mathrm{mg}$ (SIL), acetazolamide $125 \mathrm{mg}$ (ACZ) or a placebo (PLA). There was no difference in $\mathrm{VO}_{2}$ during exercise between conditions while $\mathrm{SaO}_{2}$ was greater with acetazolamide compared to both placebo and sildenafil. Acetazolamide increased ventilation (PLA 49.0 \pm 3.2 , SIL $47.7 \pm 3.1, \mathrm{ACZ} 52.1 \pm 3.0 \mathrm{l} / \mathrm{min}$ ) and reduced end-tidal $\mathrm{CO}_{2}$
\end{abstract}

(C) Springer-Verlag 2009

Correspondence to: Sophie Lalande.

Conflict of interest statement This study was conducted in accordance with the Declaration of Helsinki and approved by the Mayo Clinic Institutional Review Board. All procedures followed institutional and Health Insurance Portability and Accountability Act (HIPAA) guidelines. The authors declare that they have no conflict of interest. 
$\left(P_{\mathrm{ET}} \mathrm{CO}_{2}\right)(\mathrm{PLA} 32.1 \pm 0.8$, SIL $32.8 \pm 0.9, \mathrm{ACZ} 29.2 \pm 0.7 \mathrm{mmHg}$ ) compared to placebo and sildenafil. Breathing was less efficient with acetazolamide (increased $V_{\mathrm{E}} / V \mathrm{CO}_{2}$ ) in comparison to placebo and sildenafil (PLA $41.5 \pm 1.0$, SIL $40.4 \pm 1.3$, ACZ $45.4 \pm 1.0$ ) while sildenafil did not change $V_{\mathrm{E}} / V \mathrm{CO}_{2}$ during hypoxic exercise. In conclusion, acetazolamide increased ventilation and reduced breathing efficiency while sildenafil did not affect breathing efficiency despite a trend toward a blunted ventilatory response, possibly due to a reduction in pulmonary hypertension and/or ventilatory drive, during submaximal hypoxic exercise in healthy individuals.

\section{Keywords}

Altitude; Exercise; Sildenafil; Acetazolamide; Breathing; Ventilation

\section{Introduction}

The decreased partial pressure of oxygen at altitude results in reduced alveolar $\left(\mathrm{PAO}_{2}\right)$ and arterial $\left(\mathrm{PaO}_{2}\right)$ partial pressures of oxygen (Greene 1934). Hypoxemia stimulates the peripheral chemoreceptors which lead to an increase in ventilation in an attempt to maintain homeostasis (Rahn and Otis 1948). The maintenance of $\mathrm{PaO}_{2}$ at altitude is further complicated by increased oxygen diffusion limitations and/or ventilation-perfusion mismatching, possibly due to heterogeneous hypoxia-induced pulmonary vasoconstriction and/or transient changes in lung fluid balance (Capen and Wagner 1982; Ghofrani et al. 2004). Oxygen diffusion limitation and ventilation-perfusion mismatching may be particularly prominent during exercise (Fulco et al. 1998; Kjaergaard et al. 2007). Moreover, the hyperventilation required to increase alveolar and arterial oxygen levels during exercise may come at an increased cost as the work of breathing is $40-60 \%$ greater at altitude than at sea level for any given exercise intensity (Dempsey et al. 1977; Thoden et al. 1969).

Acetazolamide is commonly prescribed to improve arterial oxygenation and prevent acute mountain sickness in mountain climbers (Hackett and Roach 2001). Acetazolamide is a carbonic anhydrase inhibitor that decreases the renal absorption of bicarbonate and induces a metabolic acidosis which triggers an increase in ventilation and results in a lessening of hypoxemia (Faoro et al. 2007a; Swenson 1998). However, acetazolamide has been reported to reduce breathing efficiency during hypoxic exercise (Garske et al. 2003; Schoene et al. 1983), resulting in a reduced aerobic capacity and an increased perception of leg fatigue (Garske et al. 2003). Indeed, an excessive ventilatory responsiveness to hypoxic exercise due to acetazolamide would further increase the work of breathing and could result in a competition between respiratory and locomotor muscles at a time when oxygen delivery is already challenged (Smith et al. 2001). Although acetazolamide is commonly prescribed in mountain climbers, other drugs have been shown to improve arterial oxygenation at altitude.

It has been previously suggested that sildenafil decreases pulmonary hypertension and possibly mild interstitial edema at altitude, which could improve ventilation-perfusion matching and increase $\mathrm{PaO}_{2}$ (Hsu et al. 2006). Sildenafil is a phosphodiesterase-5 inhibitor that causes pulmonary vasodilation by reducing smooth muscle tone through an increase in cyclic GMP and local availability of nitric oxide resulting in a reduction in pulmonary artery pressure (Ghofrani et al. 2004; Sebkhi et al. 2003; Zhao et al. 2001). Sildenafil has been shown to attenuate the decline of arterial oxygen saturation during normobaric hypoxic exercise (Faoro et al. 2007b; Ghofrani et al. 2004; Hsu et al. 2006; Kolluru et al. 2008; Ricart et al. 2005; Zhao et al. 2001). Pulmonary hypertension and mild congestion induced by hypoxia may also stimulate ventilation through receptors such as pulmonary unmyelinated C-fiber receptors (Roberts et al. 1986). Thus, during exercise at altitude, sildenafil may not only improve breathing efficiency through altered ventilation-perfusion matching in the lung, but may also 
decrease ventilatory drive by reducing pulmonary hypertension and congestion. No previous studies directly compared the effects of sildenafil and acetazolamide on breathing efficiency during hypoxic exercise. Therefore, the purpose of this study was to examine the effects of sildenafil and acetazolamide on breathing efficiency, as measured by minute ventilation/carbon dioxide output $\left(V_{\mathrm{E}} / V \mathrm{CO}_{2}\right)$ (Kleber et al. 2000), and indices of ventilatory control during submaximal hypoxic exercise in healthy individuals.

\section{Methods}

Fifteen healthy individuals (seven men and eight women) participated in the study. Participants were excluded from the study if they had diabetes, coronary artery disease, known lung disease or renal insufficiency, hypertension (arterial blood pressure $>140 / 90 \mathrm{mmHg}$ ), severe headaches once a week or more, history of migraine headaches in the last 6 months or were taking alpha blockers or nitrates. Participants also underwent a cardiovascular and lung examination performed by a cardiologist. All participants gave written informed consent after being provided a description of study requirements. This study was conducted in accordance with the Declaration of Helsinki and approved by the Mayo Clinic Institutional Review Board. All procedures followed institutional and Health Insurance Portability and Accountability Act (HIPAA) guidelines.

\section{Study protocol}

Participants performed an incremental exercise test to exhaustion on a cycle ergometer to determine peak oxygen uptake $\left(\mathrm{VO}_{2}\right.$ peak) while breathing normal air at sea level. Initial workload was set at $30 \mathrm{~W}$ and workload was increased by $30 \mathrm{~W}$ for women and $40 \mathrm{~W}$ for men with each 2-min stages. Breath by breath data was collected and analyzed every $5 \mathrm{~s}$ using a Medical Graphics metabolic system (St Paul, MN). In an attempt to challenge lung fluid balance, participants were subsequently exposed to $18 \mathrm{~h}$ of hypoxia in an altitude tent, which included an overnight stay, on three different sessions separated by at least $24 \mathrm{~h}$. Each hypoxic exposure ended with participants performing $10 \mathrm{~min}$ of hypoxic exercise at $40 \%$ of normoxic peak $\mathrm{VO}_{2}$, a work rate simulating the level of exercise common in a mountain environment. For each visit, participants were pretreated with either $40 \mathrm{mg}$ of sildenafil (Pfizer, New York, NY), $125 \mathrm{mg}$ of acetazolamide (Pfizer, New York, NY) or placebo. Study medications were administered in a double-blind fashion at 0600, 1200 and 2200 hours on the study day and at 0600 hours the following morning (Fig. 1). The sildenafil dose was selected based on prior reports indicating good tolerability and significant hemodynamic effect at altitude (Ghofrani et al. 2004; Ricart et al. 2005) while the chosen acetazolamide dose is known to prevent periodic breathing and acute mountain sickness (Hackett et al. 1987). The dosing intervals assured that an adequate excretion of bicarbonate was achieved prior to and during hypoxic exposure, and that an adequate amount of sildenafil was present throughout the study.

Participants arrived at the laboratory at 1200 hours and were provided with a standardized meal and had free access to non-caffeinated beverages. At 1400 hours, participants entered a lowoxygen tent (Colorado Altitude Training, Boulder, $\mathrm{CO}$ ) with an oxygen concentration of $12.5 \%$ (simulated altitude of 4,300 m). Participants were given another standardized meal at 1700 hours. Participants were instructed to sleep between 2100 and 0600 hours. At 0800 hours, following $18 \mathrm{~h}$ of hypoxic exposure, participants performed $10 \mathrm{~min}$ of hypoxic exercise at $40 \%$ of peak $\mathrm{VO}_{2}$.

\section{Measurements during steady-state submaximal hypoxic exercise}

Measurements of $V \mathrm{O}_{2}, \mathrm{CO}_{2}$ output $\left(V \mathrm{CO}_{2}\right)$, minute ventilation $\left(V_{\mathrm{E}}\right)$, tidal volume $\left(V_{\mathrm{T}}\right)$, endtidal partial pressure of carbon dioxide $\left(P_{\mathrm{ET}} \mathrm{CO}_{2}\right)$, inhalation time $\left(T_{\mathrm{i}}\right)$, exhalation time $\left(T_{\mathrm{e}}\right)$ and respiration rate (RR) were made using a breath-by-breath analysis system (Medical 
Graphics St Paul, MN). Breathing efficiency was calculated as $V_{\mathrm{E}} / V \mathrm{VO}_{2}$ (Sun et al. 2002) and $V_{\mathrm{T}} / T_{\mathrm{i}}$ (Milic-Emili and Grunstein 1976) and $P_{\mathrm{ET}} \mathrm{CO}_{2}$ were used as indices of ventilatory drive. Respiratory exchange ratio (RER) was calculated as $V \mathrm{CO}_{2} / V \mathrm{O}_{2}$.

Arterial oxygen saturation $\left(\mathrm{SaO}_{2}\right)$ and heart rate were continuously monitored with a finger pulse oximeter (Nellcor N-595, Pleasanton, California). Systolic and diastolic blood pressures were measured manually by sphygmomanometry and auscultation every 2 min and values were used to calculate mean arterial pressure by the formula $[(2 \times$ diastolic blood pressure $)+$ systolic blood pressure]/3. Hypoxic ventilatory responsiveness (HVR) was calculated as (hypoxic $V_{\mathrm{E}}$ - room air $V_{\mathrm{E}}$ /hypoxic $\mathrm{SaO}_{2}$ - room air $\mathrm{SaO}_{2}$ ). Right ventricular systolic pressure was obtained by measuring the peak velocity of tricuspid regurgitation in the apical four-chamber view and approximated using the Bernoulli equation (Yock and Popp 1984). Right ventricular systolic pressure was estimated by Doppler echocardiography before exercise, immediately upon exercise completion and 10 minutes into recovery. Subjects completed the Lake Louise questionnaire for symptoms of high altitude sickness with questions ranging from gastrointestinal discomfort to evidence of systemic edema (Lake Louise consensus 1992). Lake Louise score was determined at 1400, 2000 and 0600 hours and the average value was calculated. Participants were also asked to rank their level of dyspnea, chest pain, headache and nausea. Exercise data are presented as an average of the last $7 \mathrm{~min}$ of steady-state hypoxic exercise.

\section{Statistical analysis}

A one-way analysis of variance was used to determine the effect of condition (acetazolamide, sildenafil and placebo). Where interaction effects were significant, post hoc analyses were performed with Student's paired $t$ test. Pearson's correlation coefficient was used for the analysis of associations between variables. Results are expressed as mean \pm SEM. $P$ values $<0.05$ were considered significant.

\section{Results}

\section{Ventilatory responses to hypoxic submaximal exercise}

Participants were aged $34.8 \pm 2.4$ years, measured $173.6 \pm 2.7 \mathrm{~cm}$, weighed $73.8 \pm 3.7 \mathrm{~kg}$ and had a peak $V \mathrm{O}_{2}$ of $39.3 \pm 2.6 \mathrm{ml} / \mathrm{kg} / \mathrm{min}$. There was no difference between Lake Louise scores between acetazolamide, sildenafil and placebo during hypoxic exposure. A minority of participants experienced mild dyspnea, chest pain, headaches and nausea and there was no difference between conditions. Acetazolamide increased $V_{\mathrm{E}}$ compared to placebo through an increase in $V_{\mathrm{T}}$ and a reduction in RR (Table 1). The increase in $V_{\mathrm{E}}$ resulted in a reduction in $P_{\mathrm{ET}} \mathrm{CO}_{2}$ and since $V \mathrm{CO}_{2}$ did not change, $V_{\mathrm{E}} / V \mathrm{VO}_{2}$ increased (Table $1 ;$ Fig. 2 ). $V \mathrm{O}_{2}$ and $T_{\mathrm{e}}$ did not change with acetazolamide compared to placebo (Table 1). Acetazolamide increased $T_{\mathrm{i}}$ and $V_{\mathrm{T}} / T_{\mathrm{i}}$ in comparison to placebo. RER was reduced with acetazolamide compared to placebo (Table 1).

There was a trend toward reduced $V_{\mathrm{E}}$ with sildenafil compared to placebo $(P=0.12)$ through a nearly significant reduction in $\mathrm{RR}(P=0.052)$ and an increase in $V_{\mathrm{T}}$ (Table 1 ; Fig. 2). Sildenafil increased both $T_{\mathrm{i}}$ and $T_{\mathrm{e}}$ while $V_{\mathrm{E}} / V \mathrm{CO}_{2}, P_{\mathrm{ET}} \mathrm{CO}_{2}, V \mathrm{O}_{2}$ and $V \mathrm{CO}_{2}$ did not change with sildenafil compared to placebo (Table 1; Fig. 2). The changes in $V_{\mathrm{T}}$ and $T_{\mathrm{i}}$ induced by sildenafil resulted in a tendency towards a reduction in $V_{\mathrm{T}} / T_{\mathrm{i}}$ in comparison to placebo $(P=$ $0.16)$. There was no difference in $V \mathrm{O}_{2}, V \mathrm{CO}_{2}, T_{\mathrm{i}}, T_{\mathrm{e}}$ or RR between acetazolamide and sildenafil (Table 1). Acetazolamide increased $V_{\mathrm{E}}, V_{\mathrm{T}} / T_{\mathrm{i}}, V_{\mathrm{E}} / V \mathrm{CO}_{2}$ and decreased $P_{\mathrm{ET}} \mathrm{CO}_{2}$ compared to sildenafil (Table 1; Fig. 2). 


\section{Hemodynamic responses at rest and during hypoxic exercise}

Exercising $\mathrm{SaO}_{2}$ was improved with acetazolamide, but not with sildenafil, compared to placebo (Table 2). Sildenafil increased exercising heart rate compared to acetazolamide and placebo (Table 2). Sildenafil reduced systolic blood pressure and mean arterial pressure when compared to placebo while there was no change in diastolic blood pressure during exercise between all conditions (Table 2). Right ventricular systolic pressures measured before exercise tended to be reduced with sildenafil when compared to placebo (PLA 18.2 \pm 2.1 , SIL $14.0 \pm$ 1.2 , ACZ $17.2 \pm 2.5 \mathrm{mmHg}, P=0.09)$. Right ventricular systolic pressures measured immediately after exercise were not significantly different between conditions (PLA $19.4 \pm$ 2.3, SIL 16.4 \pm 1.5 , ACZ $16.5 \pm 1.7 \mathrm{mmHg}$ ) while right ventricular systolic pressures measured 10 min after exercise were reduced with sildenafil $(P=0.04)$ and tended to be reduced with acetazolamide when compared to placebo $(P=0.07)$ (PLA 16.7 \pm 1.8 , SIL $14.9 \pm 1.4$, ACZ $14.9 \pm 1.6 \mathrm{mmHg}$ ).

\section{Discussion}

Acetazolamide increased $V_{\mathrm{E}}$ and decreased breathing efficiency during hypoxic submaximal exercise. Although sildenafil did not affect breathing efficiency, there was a trend toward a blunted ventilatory response in comparison to placebo, possibly due to pulmonary vasodilation and/or a reduction in pulmonary arterial pressure and congestion.

It is generally reported that acetazolamide increases $V_{\mathrm{E}}$ during hypoxic exercise (Garske et al. 2003; Jonk et al. 2007; McLellan et al. 1988; Schoene et al. 1983). In accordance with previous studies (Faoro et al. 2007a; Garske et al. 2003; Schoene et al. 1983), we observed that chronic intake of acetazolamide attenuated the decline in $\mathrm{SaO}_{2}$ during normobaric hypoxic exercise. Our observed acetazolamide-induced increase in $V_{\mathrm{E}}$ was sufficient to reduce the fall in $\mathrm{SaO}_{2}$ during hypoxic submaximal exercise, possibly due to increased alveolar and arterial oxygen tension. We also observed that the increase in $V_{\mathrm{E}}$ was due to an increase in $V_{\mathrm{T}}$ and a reduction in RR. Interestingly, there was an inverse correlation $(r=-0.56, P=0.02)$ between $V_{\mathrm{E}}$ and $\mathrm{SaO}_{2}$ during hypoxic exercise, indicating that individuals with greater $\mathrm{SaO}_{2}$ were actually breathing less than individuals with low $\mathrm{SaO}_{2}$. This relationship was attenuated by acetazolamide $(r=-0.40, P=0.08)$. The increase in $V_{\mathrm{E}}$ without changes in $V \mathrm{CO}_{2}$ resulted in an increased $V_{\mathrm{E}} / V \mathrm{CO}_{2}$ representing a reduced breathing efficiency, a finding previously observed during hypoxic exercise (Garske et al. 2003). The observed decrease in RER with acetazolamide was also reported by others and was suggested to be caused by an altered $\mathrm{CO}_{2}$ production kinetics (Faoro et al. 2007a; Schoene et al. 1983). Finally, acetazolamide had no effect on right ventricular systolic pressure which is consistent with the results of Faoro et al. (2007a) who reported that acetazolamide does not affect pulmonary hemodynamics.

Although there are some reports that sildenafil does not affect ventilation or breathing efficiency during normobaric or hypobaric hypoxic exercise in healthy individuals (Faoro et al. 2007b; Ricart et al. 2005), sildenafil has been observed to improve breathing efficiency during exercise in patients with heart failure (Bocchi et al. 2002; Guazzi et al. 2004; Lewis et al. 2007). This improvement in breathing efficiency in patients with heart failure was attributed to a decrease in central ventilatory drive and less likely due to an improved ventilationperfusion matching (Lewis et al. 2007). In accordance with these results, we observed that sildenafil induced a trend toward a blunted ventilatory response and reduced ventilatory drive to hypoxic submaximal exercise, which could be related to a reduction in pulmonary arterial pressures. This is supported by a near significant inverse correlation between right ventricular systolic pressure and $V_{\mathrm{E}}(r=-0.29, P=0.07)$. Figure 3 shows the $V_{\mathrm{E}} / V \mathrm{CO}_{2}$ and $P_{\mathrm{ET}} \mathrm{CO}_{2}$ relationship in all participants for all conditions. The parabola curve fitting the data was produced using the alveolar air equation as shown in Fig. 3. Since these points all fall on the same curve across conditions, it suggests that there were no changes in the physiological dead 
space fraction of the breath $\left(V_{\mathrm{D}} / V_{\mathrm{T}}\right)$, which is consistent with minimal changes in breathing pattern and/or in ventilation-perfusion matching. We did observe a decrease in right ventricular systolic pressure measurements ranging from 11 to $23 \%$ with sildenafil compared to placebo, which is consistent with previous observations that sildenafil reduced pulmonary arterial pressure through inhibition of hypoxia-induced pulmonary vasoconstriction (Faoro et al. 2007b; Ghofrani et al. 2004; Reichenberger et al. 2007). Moreover, right ventricular systolic pressures were measured at rest and not during exercise, and it is therefore possible that the sildenafil-induced reduction in pulmonary arterial pressures was greater during exercise. We also observed that acetazolamide tended to decrease right ventricular systolic pressure, possibly due to a reduced vasoconstriction from the elevated $\mathrm{SaO}_{2}$ and $\mathrm{PaO}_{2}$.

Studies examining the effects of sildenafil almost uniformly report an attenuated decline in $\mathrm{SaO}_{2}$ during acute normobaric hypoxic exercise (Faoro et al. 2007b; Ghofrani et al. 2004; Hsu et al. 2006; Ricart et al. 2005; Snyder et al. 2008). Sildenafil was reported to improve $\mathrm{SaO}_{2}$ during acute normobaric hypoxic exercise at an ambient oxygen concentration of 10\% (Faoro et al. 2007b; Ghofrani et al. 2004; Ricart et al. 2005) but did not change $\mathrm{SaO}_{2}$ during acute normobaric hypoxic exercise in an altitude tent with an ambient oxygen concentration of $12.5 \%$ (Snyder et al. 2008). Despite chronic intake of sildenafil and the accompanying hemodynamic changes, we did not observe attenuation in the decline of $\mathrm{SaO}_{2}$ during submaximal exercise following $18 \mathrm{~h}$ of hypoxic exposure. Failure to observe an improvement in $\mathrm{SaO}_{2}$ with sildenafil during hypoxic exercise may be explained by the combination of submaximal rather than maximal exercise intensity, less than $24 \mathrm{~h}$ of hypoxic exposure, as well as the milder hypoxia used in our protocol compared with studies that have either used an ambient oxygen concentration of $10 \%$ or an altitude above $5,000 \mathrm{~m}$. Our intent was to examine the effects of sildenafil and acetazolamide that could apply to typical recreational or work-related hypoxic exposures of modest duration in non-acclimatized subjects such as search and rescue or skiing trips. We believe that the benefits of sildenafil are more likely to be seen during either: (1) several days of moderate hypoxic exposure, e.g. Richalet et al. (2005), mediated by attenuation of pulmonary congestion, ventilation-perfusion mismatch and reduction in pulmonary arterial pressures; (2) more severe acute hypoxic exposure and maximal exercise (Faoro et al. 2007b; Ghofrani et al. 2004; Reichenberger et al. 2007) or (3) intense exercise in well-trained athletes under moderate or severe hypoxia where pulmonary vasodilating effects of sildenafil may be more relevant to exercise performance.

This study was performed in an altitude tent (normobaric hypoxia) and therefore may not represent the true physiological response to high altitude (hypobaric hypoxia). In addition, small effects of sildenafil on exercise $\mathrm{SaO}_{2}$ could have been missed due to limited power to detect small differences. Nonetheless it is evident that acetazolamide has greater effects than sildenafil on submaximal exercise $\mathrm{SaO}_{2}$ following $18 \mathrm{~h}$ of moderate hypoxic exposure. It would be of interest to further compare the effects of acetazolamide and sildenafil on breathing efficiency and exercise performance at different exercise intensities in a high altitude environment during several days of moderate or severe hypoxic exposure.

\section{Conclusions}

In conclusion, following $18 \mathrm{~h}$ of normobaric moderate hypoxic exposure, acetazolamide improved submaximal exercise $\mathrm{SaO}_{2}$ while reducing breathing efficiency through an increase in ventilation. In contrast, sildenafil did not significantly improve exercise $\mathrm{SaO}_{2}$, but did not impair breathing efficiency and demonstrated a trend toward a blunted ventilatory response possibly due to a reduction in pulmonary arterial pressure and/or a reduction in ventilatory drive. 


\section{Acknowledgments}

The authors would like to thank the participants for their efforts. Funding was provided by Mayo Foundation and National Institutes of Health (NIH) Grant HL71478. VKS was supported in part by NIH HL65176 and NIH MO1RR00585.

\section{References}

Bocchi EA, Guimaraes G, Mocelin A, et al. Sildenafil effects on exercise, neurohormonal activation, and erectile dysfunction in congestive heart failure: a double-blind, placebo-controlled, randomized study followed by a prospective treatment for erectile dysfunction. Circulation 2002;106:1097-1103. [PubMed: 12196335]doi:10.1161/01.CIR.0000027149.83473.B6

Capen RL, Wagner WW Jr. Intrapulmonary blood flow redistribution during hypoxia increases gas exchange surface area. J Appl Physiol 1982;52:1575-1580. [PubMed: 7201993]

Dempsey JA, Gledhill N, Reddan WG, et al. Pulmonary adaptation to exercise: effects of exercise type and duration, chronic hypoxia and physical training. Ann NY Acad Sci 1977;301:243-261. [PubMed: 270920]doi:10.1111/j.1749-6632.1977.tb38203.x

Faoro V, Huez S, Giltaire S, et al. Effects of acetazolamide on aerobic exercise capacity and pulmonary hemodynamics at high altitudes. J Appl Physiol 2007a;103:1161-1165. [PubMed: 17615281]doi: 10.1152/japplphysiol.00180.2007

Faoro V, Lamotte M, Deboeck G, et al. Effects of sildenafil on exercise capacity in hypoxic normal subjects. High Alt Med Biol 2007b;8:155-163. [PubMed: 17584010]doi:10.1089/ham.2007.1058

Fulco CS, Rock PB, Cymerman A. Maximal and submaximal exercise performance at altitude. Aviat Space Environ Med 1998;69:793-801. [PubMed: 9715971]

Garske LA, Brown MG, Morrison SC. Acetazolamide reduces exercise capacity and increases leg fatigue under hypoxic conditions. J Appl Physiol 2003;94:991-996. [PubMed: 12391068]

Ghofrani HA, Reichenberger F, Kohstall MG, et al. Sildenafil increased exercise capacity during hypoxia at low altitudes and at Mount Everest base camp: a randomized, double-blind, placebo-controlled crossover trial. Ann Intern Med 2004;141:169-177. [PubMed: 15289213]

Greene R. Observations on the composition of alveolar air on Everest, 1933. J Physiol 1934;82:481-485. [PubMed: 16994603]

Guazzi M, Tumminello G, Di Marco F, et al. The effects of phosphodiesterase-5 inhibition with sildenafil on pulmonary hemodynamics and diffusion capacity, exercise ventilatory efficiency, and oxygen uptake kinetics in chronic heart failure. J Am Coll Cardiol 2004;44:2339-2348. [PubMed: 15607396] doi:10.1016/j.jacc.2004.09.041

Hackett PH, Roach RC. High-altitude illness. N Engl J Med 2001;345:107-114. [PubMed: 11450659] doi:10.1056/NEJM200107123450206

Hackett PH, Roach RC, Harrison GL, et al. Respiratory stimulants and sleep periodic breathing at high altitude. Almitrine versus acetazolamide. Am Rev Respir Dis 1987;135:896-898. [PubMed: 3565935]

Hsu AR, Barnholt KE, Grundmann NK, et al. Sildenafil improves cardiac output and exercise performance during acute hypoxia, but not normoxia. J Appl Physiol 2006;100:2031-2040. [PubMed: 16455814]doi:10.1152/japplphysiol.00806.2005

Jonk AM, van den Berg IP, Olfert IM, et al. Effect of acetazolamide on pulmonary and muscle gas exchange during normoxic and hypoxic exercise. J Physiol 2007;579:909-921. [PubMed: 17218362] doi:10.1113/jphysiol.2006.120949

Kjaergaard J, Snyder EM, Hassager C, et al. Right ventricular function with hypoxic exercise: effects of sildenafil. Eur J Appl Physiol 2007;102:87-95. [PubMed: 17909844]doi: $10.1007 / \mathrm{s} 00421-007-0560-2$

Kleber FX, Vietzke G, Wernecke KD, et al. Impairment of ventilatory efficiency in heart failure: prognostic impact. Circulation 2000;101:2803-2809. [PubMed: 10859285]

Kolluru GK, Tamilarasan KP, Rajkumar AS, et al. Nitric oxide/cGMP protects endothelial cells from hypoxia-mediated leakiness. Eur J Cell Biol 2008;87:147-161. [PubMed: 18023499]doi: 10.1016/j.ejcb.2007.10.001 
Lake Louise consensus on definition and quantification of altitude illness. Hypoxia: mountain medicine. Burlington, Vermont: Queen City Press; 1992. p. 327-330.

Lewis GD, Lachmann J, Camuso J, et al. Sildenafil improves exercise hemodynamics and oxygen uptake in patients with systolic heart failure. Circulation 2007;115:59-66. [PubMed: 17179022]doi: 10.1161/CIRCULATIONAHA.106.626226

McLellan T, Jacobs I, Lewis W. Acute altitude exposure and altered acid-base states. I. Effects on the exercise ventilation and blood lactate responses. Eur J Appl Physiol Occup Physiol 1988;57:435444. [PubMed: 3135186]doi:10.1007/BF00417990

Milic-Emili J, Grunstein MM. Drive and timing components of ventilation. Chest 1976;70:131-133. [PubMed: 939127]

Rahn H, Otis AB. Man's respiratory response during acclimatization to high altitude. Fed Proc 1948;7:96. [PubMed: 18934474]

Reichenberger F, Kohstall MG, Seeger T, et al. Effect of sildenafil on hypoxia-induced changes in pulmonary circulation and right ventricular function. Respir Physiol Neurobiol 2007;159:196-201. [PubMed: 17851140]doi:10.1016/j.resp.2007.07.005

Ricart A, Maristany J, Fort N, et al. Effects of sildenafil on the human response to acute hypoxia and exercise. High Alt Med Biol 2005;6:43-49. [PubMed: 15772499]doi:10.1089/ham.2005.6.43

Richalet JP, Gratadour P, Robach P, et al. Sildenafil inhibits altitude-induced hypoxemia and pulmonary hypertension. Am J Respir Crit Care Med 2005;171:275-281. [PubMed: 15516532]

Roberts AM, Bhattacharya J, Schultz HD, et al. Stimulation of pulmonary vagal afferent C-fibers by lung edema in dogs. Circ Res 1986;58:512-522. [PubMed: 3698217]

Schoene RB, Bates PW, Larson EB, et al. Effect of acetazolamide on normoxic and hypoxic exercise in humans at sea level. J Appl Physiol 1983;55:1772-1776. [PubMed: 6662767]

Sebkhi A, Strange JW, Phillips SC, et al. Phosphodiesterase type 5 as a target for the treatment of hypoxiainduced pulmonary hypertension. Circulation 2003;107:3230-3235. [PubMed: 12796132]doi: 10.1161/01.CIR.0000074226.20466.B1

Smith, CA.; Dempsey, JA.; Hornbein, TF. Control of breathing at high altitude. In: Hornbein, TF.; Schoene, RB., editors. High altitude: an exploration of human adaptation. New York: Marcel Dekker, Inc.; 2001.

Snyder EM, Olson TP, Johnson BD, et al. Influence of sildenafil on lung difiusion during exposure to acute hypoxia at rest and during exercise in healthy humans. Eur J Appl Physiol 2008;103:421-430. [PubMed: 18369657]doi:10.1007/s00421-008-0735-5

Sun XG, Hansen JE, Garatachea N, et al. Ventilatory efficiency during exercise in healthy subjects. Am J Respir Crit Care Med 2002;166:1443-1448. [PubMed: 12450934]doi:10.1164/rccm.2202033

Swenson ER. Carbonic anhydrase inhibitors and ventilation: a complex interplay of stimulation and suppression. Eur Respir J 1998;12:1242-1247. [PubMed: 9877470]doi: 10.1183/09031936.98.12061242

Thoden JS, Dempsey JA, Reddan WG, et al. Ventilatory work during steady-state response to exercise. Fed Proc 1969;28:1316-1321. [PubMed: 5783538]

Yock PG, Popp RL. Noninvasive estimation of right ventricular systolic pressure by Doppler ultrasound in patients with tricuspid regurgitation. Circulation 1984;70:657-662. [PubMed: 6478568]

Zhao L, Mason NA, Morrell NW, et al. Sildenafil inhibits hypoxia-induced pulmonary hypertension. Circulation 2001;104:424-428. [PubMed: 11468204]doi:10.1161/hc2901.093117 


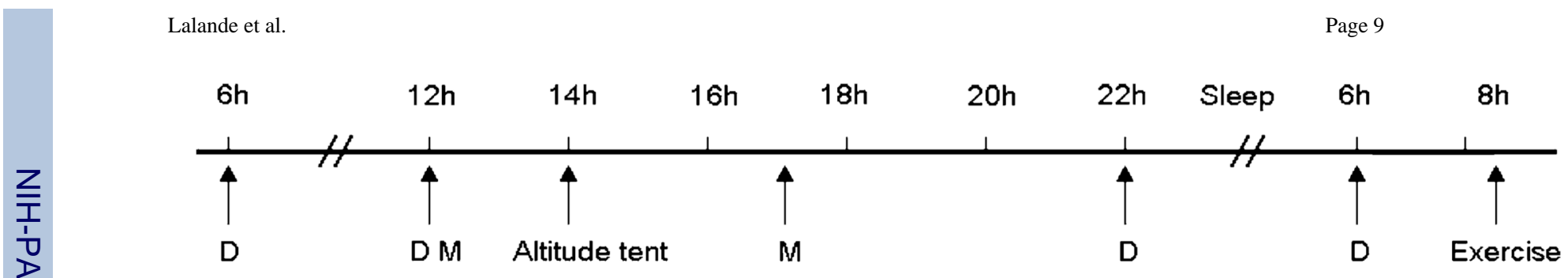

Fig. 1.

Timeline of study. $D$ drug intake, $M$ meal intake 

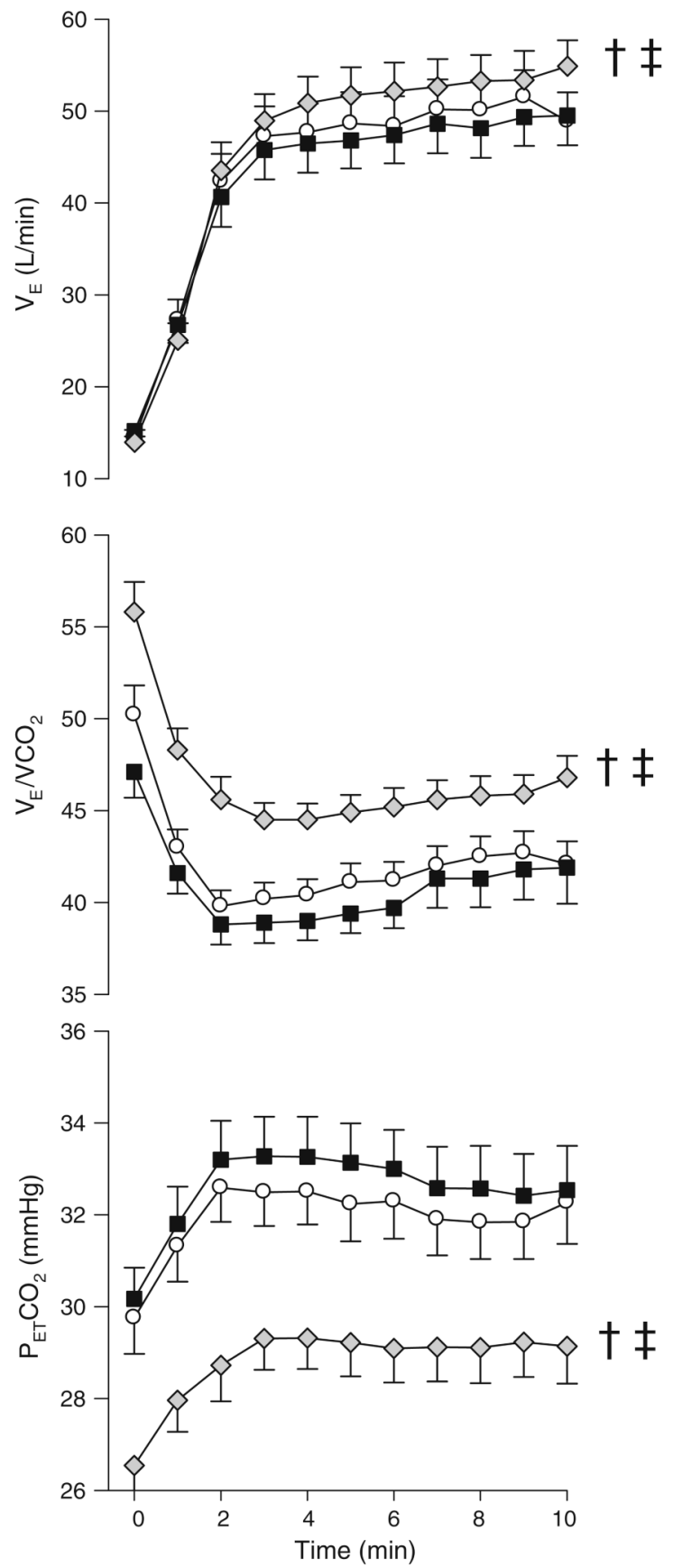

Fig. 2.

Ventilation $\left(V_{\mathrm{E}}\right)$, breathing efficiency $\left(V_{\mathrm{E}} / V \mathrm{CO}_{2}\right)$ and pressure of end-tidal $\mathrm{CO}_{2}\left(P_{\mathrm{ET}} \mathrm{CO}_{2}\right)$ during hypoxic submaximal exercise for placebo (white circles), sildenafil (black squares) and acetazolamide (gray diamonds). ${ }^{\dagger}$ Placebo versus acetazolamide, ${ }^{\ddagger}$ sildenafil versus acetazolamide 


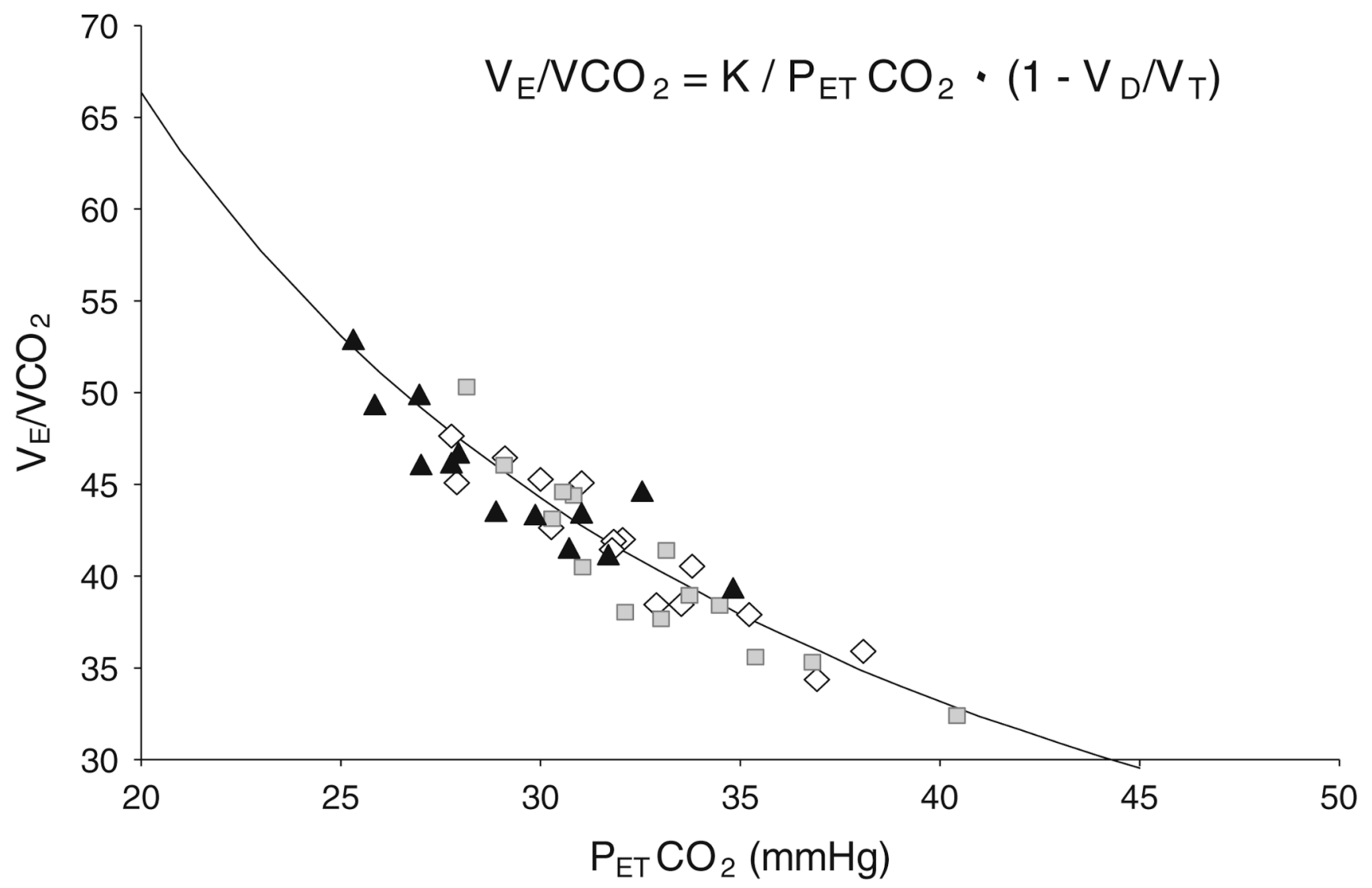

Fig. 3.

The relationship of breathing efficiency $\left(V_{\mathrm{E}} / V \mathrm{VO}_{2}\right)$ to pressure of end-tidal $\mathrm{CO}_{2}\left(P_{\mathrm{ET}} \mathrm{CO}_{2}\right)$ with acetazolamide (black triangles), placebo (open diamonds) and sildenafil (grey boxes). Moving along the parabola demonstrates differences in ventilatory drive without evidence for changes in $V_{\mathrm{D}} / V_{\mathrm{T}}$, which would theoretically shift the curve upward or downward 
Table 1

Steady-state ventilatory and gas exchange responses to hypoxic submaximal exercise following $18 \mathrm{~h}$ of hypoxic exposure

\begin{tabular}{lccc}
\hline & Placebo & Sildenafil & Acetazolamide \\
\hline$V \mathrm{O}_{2}(\mathrm{ml} / \mathrm{min})$ & $1140 \pm 65(664-1628)$ & $1201 \pm 91(695-1973)$ & $1177 \pm 86(689-2038)$ \\
$V \mathrm{CO}_{2}(\mathrm{ml} / \mathrm{min})$ & $1184 \pm 78(723-2000)$ & $1196 \pm 86(701-1916)$ & $1159 \pm 75(750-1849)$ \\
$V_{\mathrm{E}}(1 / \mathrm{min})$ & $49.0 \pm 3.2(30.0-84.0)$ & $47.7 \pm 3.1(26.7-79.2)$ & $52.1 \pm 3.0^{b, c}(34.6-80.2)$ \\
$V_{\mathrm{T}}(\mathrm{ml})$ & $1756 \pm 140(864-3003)$ & $1844 \pm 157^{a}(965-3040)$ & $1981 \pm 156^{b, c}(1193-2988)$ \\
$\mathrm{RR}(\mathrm{breath} / \mathrm{min})$ & $30 \pm 1(21-39)$ & $28 \pm 1(20-36)$ & $28 \pm 1^{b}(19-37)$ \\
$V_{\mathrm{E}} / V \mathrm{CO}_{2}$ & $41.5 \pm 1.0(34.4-47.6)$ & $40.4 \pm 1.3(32.3-50.3)$ & $45.4 \pm 1.0^{b, c}(39.4-52.9)$ \\
$P_{\mathrm{ET}} \mathrm{CO}_{2}(\mathrm{mmHg})$ & $32 \pm 1(28-38)$ & $33 \pm 1(28-40)$ & $29 \pm 1^{b, c}(25-35)$ \\
$\mathrm{RER}$ & $1.04 \pm 0.03(0.86-1.23)$ & $1.00 \pm 0.02(0.90-1.10)$ & $0.99 \pm 0.02^{b}(0.91-1.24)$ \\
$T_{\mathrm{i}}(\mathrm{s})$ & $0.90 \pm 0.05(0.64-1.34)$ & $0.96 \pm 0.06^{a}(0.65-1.44)$ & $0.97 \pm 0.06^{b}(0.64-1.49)$ \\
$T_{\mathrm{e}}(\mathrm{s})$ & $1.27 \pm 0.07(0.84-1.74)$ & $1.37 \pm 0.07^{a}(1.04-1.97)$ & $1.32 \pm 0.07(0.92-1.90)$ \\
$V_{\mathrm{T}} / T_{\mathrm{i}}$ & $1.94 \pm 0.11(1.16-3.19)$ & $1.91 \pm 0.11(1.07-2.98)$ & $2.04 \pm 0.11^{b, c}(1.30-3.11)$ \\
$\mathrm{HVR}$ & $1.78 \pm 0.50(0.06-5.71)$ & $1.86 \pm 0.57(0.26-7.19)$ & $1.97 \pm 0.36(0.57-3.57)$ \\
\hline
\end{tabular}

$V O_{2}$, oxygen uptake; $V \mathrm{CO}_{2}$, carbon dioxide output; $V_{\mathrm{E}}$, minute ventilation; $V_{\mathrm{T}}$, tidal volume; $P_{\mathrm{ETCO}}$, end-tidal partial pressure of carbon dioxide; $T_{\mathrm{i}}$, inhalation time; $T_{\mathrm{e}}$, exhalation time, $\mathrm{RR}$, respiration rate; $V_{\mathrm{E}} / V_{\mathrm{CO}}$, breathing efficiency; $V_{\mathrm{T}} / T_{\mathrm{i}}$, ventilatory drive; RER, respiratory exchange ratio; HVR, hypoxic ventilatory responsiveness

${ }^{a}$ Placebo versus sildenafil

${ }^{b}$ Placebo versus acetazolamide

${ }^{c}$ Sildenafil versus acetazolamide 
Table 2

Steady-state cardiovascular responses to hypoxic submaximal exercise following $18 \mathrm{~h}$ of hypoxic exposure

\begin{tabular}{lccc}
\hline & Placebo & Sildenafil & Acetazolamide \\
\hline $\mathrm{SaO}_{2}(\%)$ & $88.1 \pm 0.7(84.5-94.4)$ & $88.7 \pm 0.7(83.9-92.1)$ & $89.3 \pm 0.8^{b}(82.1-94.3)$ \\
$\mathrm{HR}(\mathrm{bpm})$ & $128 \pm 4(109-158)$ & $133 \pm 5^{a}(104-163)$ & $129 \pm 5^{c}(99-158)$ \\
$\mathrm{SBP}(\mathrm{mmHg})$ & $144 \pm 5(118-178)$ & $140 \pm 5^{a}(119-177)$ & $140 \pm 6(93-171)$ \\
$\mathrm{DBP}(\mathrm{mmHg})$ & $71 \pm 6(58-99)$ & $67 \pm 6(53-95)$ & $70 \pm 5(62-89)$ \\
$\mathrm{MAP}(\mathrm{mmHg})$ & $95 \pm 5(80-122)$ & $92 \pm 5^{a}(75-122)$ & $93 \pm 5(79-110)$ \\
\hline
\end{tabular}

$\mathrm{SaO}_{2}$, arterial oxygen saturation; $\mathrm{HR}$, heart rate; $\mathrm{SBP}$, systolic blood pressure; $\mathrm{DBP}$, diastolic blood pressure; MAP, mean arterial pressure

$a_{\text {Placebo versus sildenafil }}$

${ }^{b}$ Placebo versus acetazolamide

${ }^{c}$ Sildenafil versus acetazolamide 